\title{
Extrapulmonary involvement associated with Mycoplasma pneumoniae infection
}

\author{
T Liong, KL Lee, YS Poon, SY Lam, KM Kwok, WF Ng, TL Lam, KI Law *
}

\section{A B S T R A C T}

Mycoplasma pneumoniae infection usually presents with upper and lower respiratory tract infection. Extrapulmonary involvement is not uncommon, however. We report two cases of predominantly extrapulmonary manifestations of Mycoplasma pneumoniae infection without significant pulmonary involvement. Both cases were diagnosed by serology. These cases illustrate the diversity of clinical presentations of Mycoplasma pneumoniae infection. Clinicians should maintain a high index of suspicion.
Hong Kong Med J 2015;21:569-72

DOI: 10.12809/hkmj144403

${ }^{1}$ T Liong, FHKCP, FHKAM (Medicine)

${ }^{1}$ KL Lee, FHKCP, FHKAM (Medicine)

${ }^{1}$ YS Poon, FHKCP, FHKAM (Medicine)

${ }^{1}$ SY Lam, FHKCP, FHKAM (Medicine)

KM Kwok, MRCP

${ }^{2}$ WF Ng, FHKAM (Pathology)

${ }^{2}$ TL Lam, FHKAM (Pathology)

${ }^{1}$ KI Law *, FHKCP, FHKAM (Medicine)

1 Intensive Care Unit

${ }^{2}$ Department of Pathology

United Christian Hospital, Kwun Tong, Hong Kong

* Corresponding author: lawki@ha.org.hk

\section{Case reports}

\section{Case 1}

A 20-year-old man who worked as a car mechanic and enjoyed good health presented to United Christian Hospital in Hong Kong in August 2013 after collapsing suddenly at work. Ventricular arrhythmia was detected by ambulance men and defibrillation was performed 3 times with an automated external defibrillator. He was then transferred to the emergency department of the same hospital where he was observed to have persistent ventricular tachycardia and fibrillation. Advanced cardiac life support was continued, repeated defibrillation was performed and spontaneous circulation was restored 53 minutes later when he was then intubated.

Initial electrocardiogram after successful resuscitation showed diffuse ST elevation over the chest leads (Fig 1). Echocardiogram revealed poor left ventricular systolic function with global

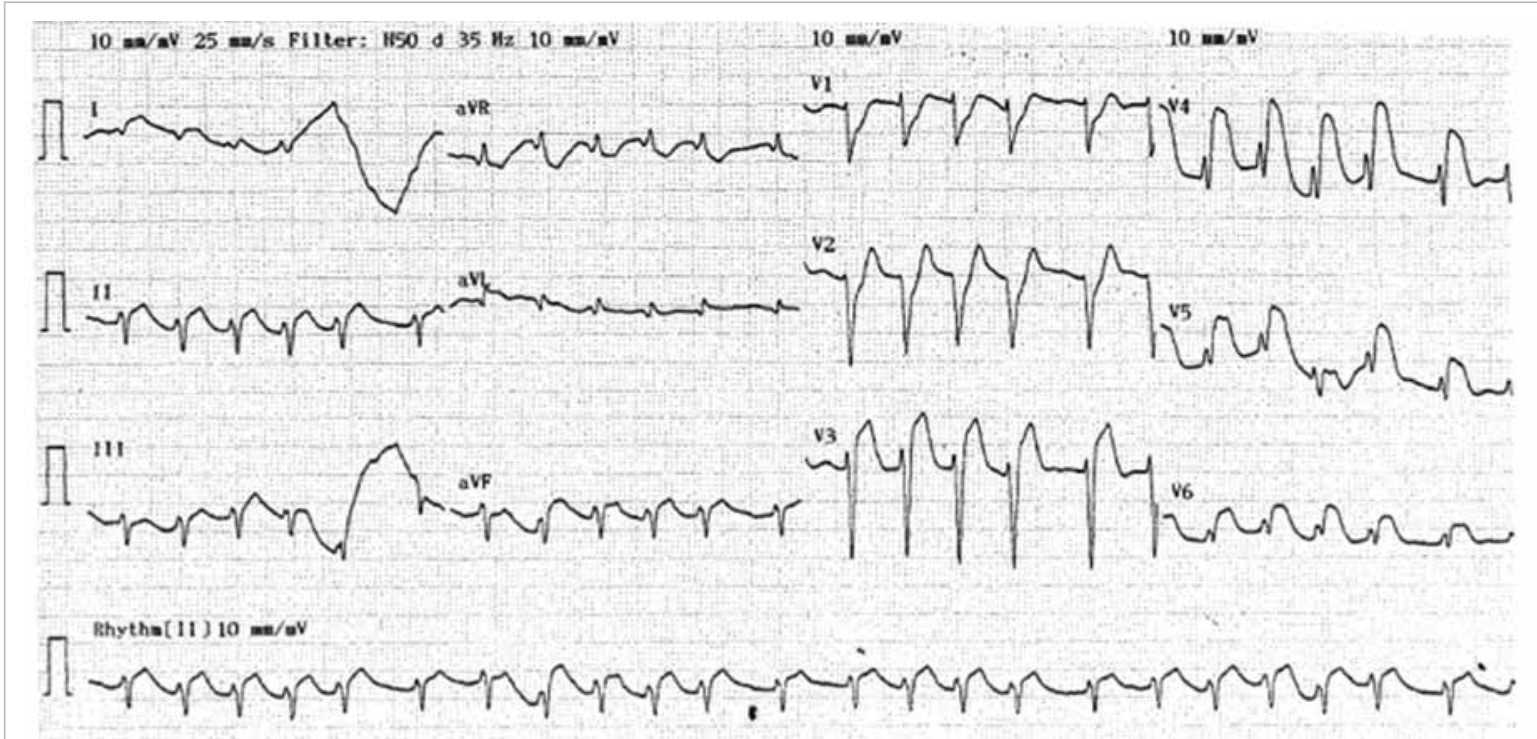

FIG I. Initial electrocardiogram of case I 


\section{與肺炎支原體感染相關的肺外併發症}

\section{梁婷、李家龍、潘逸隌、林兆源、郭家明、吳榮豐、林鐵樑、 羅建業}

由肺炎支原體引致的疾病一般分為上呼吸道和下呼吸道感染, 但有肺 外表現的也有不少。本文報告有肺外表現的肺炎支原體感染的兩個病 例, 他們均透過血清學確診, 並沒有顯著累及肺部。這兩個病例顯示 肺炎支原體感染的臨床表現多樣性，因此醫生應保持高度警惕。
Serology for viral studies was all negative. Nonetheless, paired serology for Mycoplasma pneumoniae on 26 August 2013 and 4 September 2013 showed a 4-fold decrease in antibody titres from 1:160 to $1: 40$, suggestive of recent $M$ pneumoniae infection. Postmortem examination showed diffuse lymphocytic infiltrates and extensive myocardial necrosis within myocardial fibres (Fig 2). Reversetranscriptase polymerase chain reaction (RT-PCR) for $M$ pneumoniae on bilateral lung tissue and myocardium were negative.

\section{Case 2}

hypokinesia. Ad-hoc cardiac catheterisation was carried out. There was no coronary lesion and the patient was transferred to the intensive care unit (ICU) for therapeutic hypothermia.

On arrival in ICU, the patient had a high fever up to $39.7^{\circ} \mathrm{C}$. Blood pressure was normal on lowdose inotropes and pulse rate was 140 beats/minute. Glasgow Coma Scale score was 2 for eye opening, 1 for verbal response, and 1 for motor response. His pupils were equal and reactive, and bilateral plantar reflexes were equivocal. Frothy sputum was evident from the endotracheal tube but physical examination was otherwise unremarkable.

Initial blood tests revealed elevated white cell count (WCC) of $25.1 \times 10^{9} / \mathrm{L}$ (reference range [RR], 3.9-9.3 $\times 10^{9} / \mathrm{L}$ ), neutrophilia of $21.6 \times 10^{9} / \mathrm{L}$ (RR, $\left.1.8-6.2 \times 10^{9} / \mathrm{L}\right)$, and normal lymphocyte count of $2.9 \times 10^{9} / \mathrm{L}\left(\mathrm{RR}, 1.0-3.2 \times 10^{9} / \mathrm{L}\right)$. Haemoglobin level and platelet count were normal. He had mild renal and liver impairment with urea $8.2 \mathrm{mmol} / \mathrm{L}$ (RR, 2.8-8.1 $\mathrm{mmol} / \mathrm{L}$ ) and creatinine $138 \mu \mathrm{mol} / \mathrm{L}$ (RR, 62-106 $\mu \mathrm{mol} / \mathrm{L})$. Sodium and potassium levels were normal and alanine transferase (ALT) was $152 \mathrm{IU} / \mathrm{L}$ (reference level [RL], $<41 \mathrm{IU} / \mathrm{L}$ ). Creatinine kinase was $6439 \mathrm{IU} / \mathrm{L}$ (RR, 39-308 IU/L), and troponin I was $12886 \mathrm{ng} / \mathrm{L}$ (RL, $\leq 14 \mathrm{ng} / \mathrm{L})$. Initial urine toxic screening was negative. His first chest X-ray (CXR) showed right upper lobe consolidation, but repeated CXR the next morning showed almost complete resolution. Initial computed tomography (CT) of the brain was unremarkable.

Amoxicillin/clavulanate was started to cover aspiration pneumonia. Therapeutic hypothermia for neuroprotection and continuous veno-venous haemofiltration for acute kidney injury were commenced. On day 4 the patient developed convulsions and repeated CT brain showed diffuse cerebral oedema. An electroencephalogram showed diffuse encephalopathy compatible with severe hypoxic-ischaemic insult. The patient remained in a vegetative state and a tracheostomy was performed. He had repeated episodes of ventilator-associated pneumonia that were unresponsive to multiple regimens of antibiotics and finally succumbed on day 24 of admission.
A 57-year-old security guard with a history of infrequent asthma attacks but no regular followup attended the emergency department of United Christian Hospital in September 2013 with fever, chills, and rigors. He also complained of a new-onset developed 1 day prior to admission. He volunteered that he was constantly exposed to insect bites due to the close proximity of rural areas to his working environment.

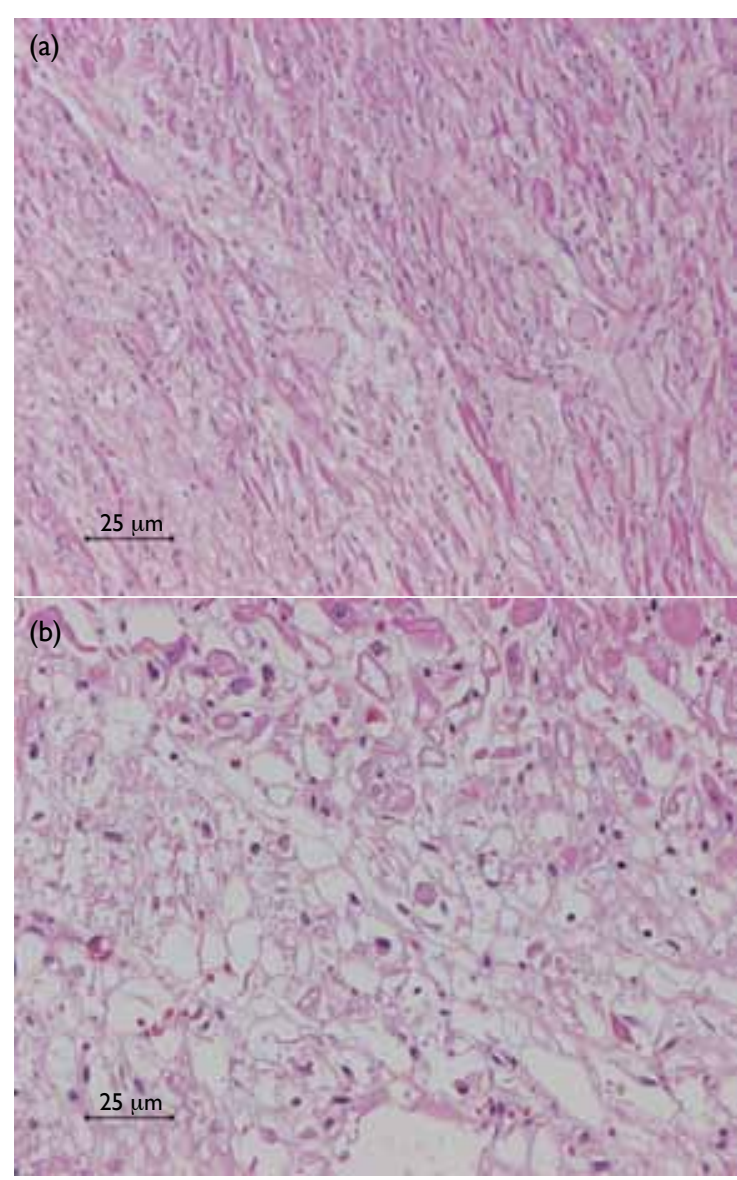

FIG 2. Case I: (a) lymphocytic infiltrates within myocardial fibres (H\&E; original magnification, $x$ 200); (b) extensive myocardial necrosis (H\&E; original magnification, $x$ 400) maculopapular rash over the trunk and limbs that 
After admission to the medical ward, he developed a high fever of $40.3^{\circ} \mathrm{C}$. Blood pressure was normal and pulse rate was 110 beats/minute. Oxygen saturation could be maintained on low-flow oxygen. Physical examination of the cardiovascular system, chest, and abdomen was normal but a maculopapular rash compatible with erythema multiforme over the back, lower abdomen, and bilateral lower limbs was observed. No eschar could be seen.

Initial investigations revealed the following: elevated WCC at $22.1 \times 10^{9} / \mathrm{L}$, neutrophilia of $21 \times 10^{9} / \mathrm{L}$, and lymphopenia of $0.2 \times 10^{9} / \mathrm{L}$. The haemoglobin level was $117 \mathrm{~g} / \mathrm{L}$ (RR, 135-173 $\mathrm{g} / \mathrm{L}$ ) and platelet count was $79 \times 10^{9} / \mathrm{L}$ (RR, $\left.160-420 \times 10^{9} / \mathrm{L}\right)$. The clotting profile was mildly deranged, with international normalised ratio of 1.3. He also had mild renal and liver impairment: creatinine $111 \mu \mathrm{mol} / \mathrm{L}$, ALT $74 \mathrm{IU} / \mathrm{L}$, and aspartate aminotransferase $101 \mathrm{IU} / \mathrm{L}$. Initial CXR did not reveal any consolidative changes.

Amoxicillin/clavulanate was commenced but the patient's condition deteriorated with development of septic shock that required high-dose inotropes, type I respiratory failure requiring high-flow oxygen, acute kidney injury, and disseminated intravascular coagulopathy despite change in antibiotic therapy to piperacillin/tazobactam and azithromycin soon after admission. He was transferred to ICU on day 3 of admission and required intubation due to aspiration. Antibiotics were changed to piperacillin/tazobactam and doxycycline. His condition gradually improved and he was successfully extubated and weaned off all inotropes. The skin rash also resolved spontaneously and repeated biochemistry tests revealed complete resolution of renal and liver derangement.

Skin biopsy was not performed. The Widal test and Weil-Felix tests were all negative. Paired serology of $M$ pneumoniae showed a 4-fold rise in antibody titres from 1:<10 to $1: 40$, with confirmation of $M$ pneumoniae infection. Viral serology for rubella and salmonella was not increased.

\section{Discussion}

We report two cases of $M$ pneumoniae infection that presented with extrapulmonary symptoms and no significant respiratory involvement. Mycoplasma pneumoniae usually infects the upper and lower respiratory tract. Up to $50 \%$ of patients develop only mild upper respiratory tract symptoms such as cough, sore throat, malaise, and only $3 \%$ to $10 \%$ of patients develop pneumonia. ${ }^{1}$

Approximately $25 \%$ of patients infected with $M$ pneumoniae develop extrapulmonary complications. This can happen before, during, or after the onset of or even in the absence of respiratory symptoms. ${ }^{1}$ An autoimmune reaction has been suggested as the pathogenesis of many of these extrapulmonary complications. ${ }^{1}$ The presence of organisms at an extrapulmonary site, however, suggests that direct invasion is also an important mechanism..$^{2,3}$

The extrapulmonary manifestations associated with $M$ pneumoniae may be neurological, cardiac, dermatological, musculoskeletal, haematological, and gastro-intestinal. ${ }^{4}$ Of these, neurological and dermatological symptoms are recognised as among the most common extrapulmonary manifestations of $M$ pneumoniae infection. ${ }^{1,4}$

A wide range of dermatological manifestations has been described in patients with $M$ pneumoniae infection. Mild symptoms include a maculopapular or vesicular rash. ${ }^{5}$ Erythema multiforme and StevensJohnson syndrome have a strong association with $M$ pneumoniae infection. ${ }^{4,6-8}$

The patient in case 2 presented with sepsis and erythema multiforme. He was not prescribed any medication associated with erythema multiforme. Since a list of infective causes of erythema multiforme had been excluded by serology tests, his skin manifestation was most likely due to $M$ pneumoniae infection.

Cardiac involvement is regarded as an uncommon complication of $M$ pneumoniae infection. ${ }^{1}$ Pericarditis, myocarditis or pericardial effusion with or without tamponade effect have been described. ${ }^{1}$ It is more commonly found in adults than in paediatric patients. ${ }^{9}$ Fortunately, the outcome is generally good. Only a minority of patients had longterm sequelae and mortality is rare. ${ }^{10}$

Myocarditis associated with $M$ pneumoniae infection that presents with ventricular arrhythmia as in case 1 is rare. We excluded other common causes of ventricular arrhythmia by initial blood tests, toxic screening, cardiac catheterisation, and CT brain. A 4-fold decrease in antibody titre of paired sera confirmed recent $M$ pneumoniae infection. Autopsy results showed lymphocytic myocarditis. It is plausible, although not confirmative, that $M$ pneumonia-associated myocarditis due to direct invasion of $M$ pneumoniae cannot be shown by RT-PCR. Other differential diagnoses of lymphocytic myocarditis such as viral myocarditis were excluded by viral serology.

In addition to the diverse clinical manifestations, clinicians should also be aware of widespread macrolide resistance of $M$ pneumoniae in Asia, including Hong Kong. ${ }^{11}$ High rates of macrolide resistance of up to $70 \%$ to $80 \%$ have been reported in China and Japan. ${ }^{12-14}$ Prompt adjustment of antibiotics to cover atypical pathogens is essential to successful treatment, as in our second patient. Consideration of alternatives such as doxycycline or fluoroquinolones as empirical treatment of atypical pathogens in areas with high rates of resistance may be appropriate. ${ }^{14}$

In conclusion, although $M$ pneumoniae most 
commonly presents with respiratory tract symptoms, extrapulmonary manifestations are not uncommon. Clinicians should be aware of variable clinical presentations of $M$ pneumoniae and macrolide resistance in our locality.

\section{References}

1. Waites KB, Talkington DF. Mycoplasma pneumoniae and its role as a human pathogen. Clin Microbiol Rev 2004;17:697-728.

2. Kasahara I, Otsubo Y, Yanase T, Oshima H, Ichimaru $\mathrm{H}$, Nakamura $\mathrm{M}$. Isolation and characterization of Mycoplasma pneumoniae from cerebrospinal fluid of a patient with pneumonia and meningoencephalitis. J Infect Dis 1985;152:823-5.

3. Saïd MH, Layani MP, Colon S, Faraj G, Glastre C, Cochat P. Mycoplasma pneumoniae-associated nephritis in children. Pediatr Nephrol 1999;13:39-44.

4. Sánchez-Vargas FM, Gómez-Duarte OG. Mycoplasma pneumoniae-an emerging extra-pulmonary pathogen. Clin Microbiol Infect 2008;14:105-17.

5. Baum SG. Mycoplasma pneumoniae infection in adults. Available from: http://www.uptodate.com/ contents/mycoplasma-pneumoniae-infection-inadults? source $=$ search_result $\&$ search $=$ Mycoplasma + pne umoniae+infection+in+adults.\&selectedTitle $=1 \% 7 \mathrm{E} 116$. Accessed Aug 2015.

6. Vanfleteren I, Van Gysel D, De Brandt C. Stevens-Johnson syndrome: a diagnostic challenge in the absence of skin lesions. Pediatr Dermatol 2003;20:52-6.

7. Vargas-Hitos JA, Manzano-Gamero MV, Jiménez-Alonso J. Erythema multiforme associated with Mycoplasma pneumoniae. Infection 2014;42:797-8.

8. Rock N, Belli D, Bajwa N. Erythema bullous multiforme: a complication of Mycoplasma pneumoniae infection. J Pediatr 2014;164:421.

9. Formosa GM, Bailey M, Barbara C, Muscat C, Grech V. Mycoplasma pneumonia-an unusual cause of acute myocarditis in childhood. Images Paediatr Cardiol 2006;8:7-10.

10. Paz A, Potasman I. Mycoplasma-associated carditis. Case reports and review. Cardiology 2002;97:83-8.

11. Ho PL, Wong SY, editors. Reducing bacterial resistance with IMPACT-Interhospital Multi-disciplinary Programme on Antimicrobial ChemoTherapy. 4th ed. Hong Kong SAR: Centre for Health Protection; 2012.

12. Yin YD, Cao B, Wang H, et al. Survey of macrolide resistance in Mycoplasma pneumoniae in adult patients with community-acquired pneumonia in Beijing, China [in Chinese]. Zhonghua Jie He He Hu Xi Za Zhi 2013;36:9548.

13. Eshaghi A, Memari N, Tang P, et al. Macrolide-resistant Mycoplasma pneumoniae in humans, Ontario, Canada, 2010-2011. Emerg Infect Dis 2013;19(9). doi: 10.3201/ eid1909.121466.

14. Okada T, Morozumi M, Tajima T, et al. Rapid effectiveness of minocycline or doxycycline against macrolide-resistant Mycoplasma pneumoniae infection in a 2011 outbreak among Japanese children. Clin Infect Dis 2012;55:1642-9. 